\title{
Predicting Hydraulic Conductivity (k) of Tropical Soils by using Artificial Neural Network (ANN)
}

\author{
Lim, D.K.H ${ }^{1}$. and Kolay, P.K .
}

\begin{abstract}
Hydraulic conductivity of tropical soils is very complex. Several hydraulic conductivity prediction methods have focused on laboratory and field tests, such as the Constant Head Test, Falling Head Test, Ring Infiltrometer, Instantaneous profile method and Test Basins. In the present study, Artificial Neural Network (ANN) has been used as a tool for predicting the hydraulic conductivity $(k)$ of some tropical soils. ANN is potentially useful in situations where the underlying physical process relationships are not fully understood and well-suited in modeling dynamic systems on a real-time basis. The hydraulic conductivity of tropical soil can be predicted by using ANN, if the physical properties of the soil e.g., moisture content, specific gravity, void ratio etc. are known. This study demonstrates the comparison between the conventional estimation of $k$ by using Shepard's equation for approximating $k$ and the predicted $k$ from ANN. A programme was written by using MATLAB 6.5.1 and eight different training algorithms, namely Resilient Backpropagation (rp), Levenberg-Marquardt algorithm (lm), Conjugate Gradient Polak-Ribiére algorithm (cgp), Scale Conjugate Gradient (scg), BFGS QuasiNewton (bfg), Conjugate Gradient with Powell/Beale Restarts (cgb), Fletcher-Powell Conjugate Gradient (cgf), and One-step Secant (oss) have been compared to produce the best prediction of $k$. The result shows that the network trained with Resilient Backpropagation (rp) consistently produces the most accurate results with a value of $\mathrm{R}=0.8493$ and $\mathrm{E}^{2}=0.7209$.
\end{abstract}

Keywords: Tropical Soils, Hydraulic Conductivity, Artificial Neural Network (ANN)

\section{INTRODUCTION}

Soils are extremely heterogeneous and the magnitude of its hydraulic conductivity is very complex. In general, the Shydraulic conductivity of the soil depends on several factors, including the particle size, porosity and the bulk density of the soil. Hydraulic conductivity of soils is divided into saturated hydraulic conductivity, $\mathrm{k}_{\mathrm{s}}$, and unsaturated hydraulic conductivity, $\mathrm{k}_{\mathrm{u}}$. It is measured in horizontal permeability, $\mathrm{k}_{\mathrm{H}}$ and vertical permeability, $\mathrm{k}_{\mathrm{V}}$. Overall permeability is then then obtained by

$$
k=\sqrt{k_{H} \cdot k_{V}}
$$

Many hydraulic conductivity prediction methods have focused on correlations with laboratory and field tests, such as Constant Head Test, Falling Head Test, Ring Infiltrometer, Instantaneous profile method and Test Basins [1]. Field test gives advantages as the soil profile is often undisturbed but we are unable to control the soil environment. For laboratory tests, obtaining an undisturbed sample is difficult but we could test the soil in a controlled environment. However, most of the available methods are restricted by simplification of the problem by incorporating several assumptions for the factors that determine the hydraulic conductivity of the soil. Sometimes, these methods are quite costly as well.

There were several attempts to predict the hydraulic conductivity of soils from its physical characteristics in the literature. Cronican and Gribb produced equations for predicting hydraulic conductivity based on grain-size data [2]. Nemati et al. came out with another method to predict hydraulic conductivity changes from aggregate mean weight diameter based on the study of the decrease in mean weight diameter of aggregates exposed to different rates of wetting [3]. Poulsen et al. did a study on predicting saturated and unsaturated hydraulic conductivity in undisturbed soils from soil water characteristics [4]. Each of these methods is of great practical importance, because it permits the prediction of the hydraulic conductivity of the soil, without conducting field and or laboratory tests. It seems, however, that very few universally accepted methods that have been proposed for predicting the hydraulic conductivity of the soil.

1 Student, Department of Civil Engineering, Faculty of Engineering, Universiti Malaysia Sarawak, Sarawak, Malaysia, godspilla@gmail.com 2 Senior Lecturer, Department of Civil Engineering, Faculty of Engineering, , Universiti Malaysia Sarawak, Sarawak, Malaysia, kkprabir@feng.unimas.myor,pkolay2001@yahoo.com, 
Hydraulic conductivity of soils $(k)$ can be determined for various types of soils. Several equations are available by various researchers [5-9] for calculating the $k$ from the physical properties of the soil.

Hydraulic conductivity prediction is one of the most challenging geotechnical engineering problems because a considerable level of uncertainty often affects it which in turn influences designs. Several researchers [4, 10-13] have predicted hydraulic conductivity by considering different uncertainty parameters, neural networks, analytical methods, regression analysis and simplified methods.

Each soil has unique properties that differentiate it from the others. An estimation of the hydraulic conductivity $(k)$ by using tests in laboratory takes long time and also sample disturbance may occur while conducting the test. In that situation, Artificial Neural Network (ANN) is potentially useful, where the underlying physical process relationships are not fully understood and well-suited in modelling dynamic systems on a real-time basis, for predicting the hydraulic conductivity characteristics of the soft soil. The hydraulic conductivity characteristics of the tropical soils can be predicted by using ANN, if the physical properties of the soils are known. It will be much more convenient and economical compared to even laboratory tests for calculating and predicting the hydraulic conductivity characteristics of tropical soils. Hence, in this paper an attempt has been made to predict the hydraulic conductivity of tropical soils by using ANN.

\section{ARTIFICIAL NEURAL NETWORK (ANN)}

Artificial neural network (ANN) is a form of artificial intelligence (AI), which attempts to simulate the biological structure of the human brain and nervous system in their architecture. The key element of this paradigm is the novel structure of the information processing system. It is composed of a large number of highly interconnected processing elements (neurons), working together to solve a particular problems. Like human beings, ANNs also learn by example. An ANN is set for a specific application, such as pattern recognition or data classification, through a learning process.

There are various sorts of artificial neural networks which differ in their functions, such as data prediction, data classification, data association, data conceptualization, and data filtering. The common type of ANN consists of three interconnected layers: input layer, hidden layer and output layer. Multi-layered networks use a variety of learning techniques; the most popular is back-propagation. In this method, the output values are compared with the correct answer to compute the value of some predefined error-functions. By various techniques, the error is then fed back through the network. Using this information, the algorithm adjusts the weights of each connection in order to reduce the value of the error function by some small amount.

Back-propagation networks are probably the most well known and widely applied of the neural networks today. In essence, the back-propagation network is a perceptron with multiple layers, a different threshold function in the artificial neuron, and a more robust and capable learning rule. ANNs do not have any prior knowledge about the existing problem. Therefore, training is required to make the network more intelligent. The ANN is trained with a set of input and known output pairs known as the training set. At the beginning of the training process, the network is initialised with the data provided from the laboratory. The weights are optimised to gain a specific response from the ANN. The process of optimisation or training is essential in ANN models. This is because when these weights are modified, data transfer through the ANN changes and the overall network performance alters.

The most important step in designing an ANN is the determination of the ANN architecture and the selection of the training algorithm. An optimal architecture is able to obtain good performance with minimal resulting errors. It must also retain a simple and compact structure.

No unified theory exists to determine which optimal architecture bests suits a project and very often, more than one ANN can produce similar results. The numbers of input and output nodes are problem dependent. The main problem is the difficulty in selecting the number of hidden layers and in assigning the number of nodes to each of these layers. A trial-anderror procedure is generally adopted to determine the optimal architecture.

\section{APPLICATION OF ANN IN GEOTECHNICAL ENGINEERING}

Over the past decades, ANNs have been applied to various geotechnical engineering applications. For example, Lee and Sterling produced a neural network for identification of probable failure modes for underground openings from prior case history information [14]. Besides that, Penumadu et al. have attempted to model the stress-strain behaviour of clays, incorporating rate dependant behaviour [15]. Lee and Lee study utilised neural networks to predict the ultimate bearing capacity of piles [16]. Sivakugan et al. studied the possibility of using neural networks to predict the settlement of shallow foundations on granular soils [17]. Kolay et al. have used a back-propagation method for neural networks in predicting settlement of tropical soft soil [18]. Apart from that, there was also involvement of ANNs in seismic liquefaction assessment [19]. 
Several researchers, as mentioned above, have studied the different aspects in geotechnical engineering by using ANN modelling. However, the application of ANN in predicting the hydraulic conductivity of tropical soils in Sarawak, Malaysia is not available. Thus, the present study concentrates on predicting the hydraulic conductivity of tropical soils by using ANN programming.

\section{METHODLOGY}

In this research, 8 different MATLAB 6.5.1 training algorithms have been applied to the network, namely Resilient Backpropagation (rp), Levenberg-Marquardt algorithm (lm), Conjugate Gradient Polak-Ribiére algorithm (cgp), Scale Conjugate Gradient (scg), BFGS Quasi-Newton (bfg), Conjugate Gradient with Powell/Beale Restarts (cgb), Fletcher-Powell Conjugate Gradient (cgf), and One-step Secant (oss). Every training algorithm has its own special characteristics towards the network and differs in its simulated results.

In any training algorithm, the aim is to reduce the global error, E which is defined as

$$
E=\frac{1}{p} \sum_{P=1}^{P} E_{p}
$$

Where, $P=$ total number of training patterns; and $E_{p}=$ error for training pattern, $p$

$$
E_{p}=\frac{1}{2} \sum_{k=0}^{N}\left(o_{k}-t_{k}\right)^{2}
$$

Where, $N=$ total number of output nodes; $o_{k}=$ network output at the $k$ th output node; and $t_{k}=$ target output at the $k$ th output node.

In the present study, feed-forward back-propagation neural network with 1 hidden layer is utilised for data prediction. The network was trained using 8 different patterns of back-propagation algorithms. A different number of neurons in the hidden layer of the neural network will result in a different simulated result. Therefore, in this study, 2, 4, 6, 8, 10, 20, and 30 neurons have been used in the program. Learning rates were also applied to the network so that a better training could be achieved. The training rates of the networks examined are 0.01, 0.03, 0.05, 0.07, and 0.09.

MATLAB 6.5.1 is utilised in training and simulation of data. The parameters that have been investigated and analysed are (a) Number of neurons in the hidden layer; (b) Learning algorithms; (c) Learning rates.

The performances of the networks were measured by coefficient of correlation, $R$, and coefficient of efficiency (NashSutcliffe equation), $E^{2}$. Value of $R$ is given by the following equation:

$$
R=\frac{\sum_{i=1}^{i=n}\left[Q_{m}\left(t_{i}\right)-\overline{Q_{m}\left(t_{i}\right)}\right]\left[Q_{s}\left(t_{i}\right)-\overline{\left.Q_{s}\left(t_{i}\right)\right]}\right)}{\sqrt{\sum_{i=1}^{i=n}\left[Q_{m}\left(t_{i}\right)-\overline{Q_{m}\left(t_{i}\right)}\right]^{2} \sum\left[Q_{s}\left(t_{i}\right)-\overline{Q_{s}\left(t_{i}\right)}\right]^{2}}}
$$

Where, subscript $m$ and $s$ represent the observed and simulated $C_{c}$ respectively while $\overline{Q_{m}}$ and $\overline{Q_{s}}$ are average of the observed and simulated $C_{c}$. Nash-Sutcliffe coefficient, $E^{2}$ is expressed as:

$$
E^{2}=1-\frac{\sum_{i=1}^{i=n}\left[Q_{m}\left(t_{i}\right)-Q_{s}\left(t_{i}\right)\right]^{2}}{\sum_{i=1}^{i=n}\left[Q_{m}\left(t_{i}\right)-\overline{Q_{m}}\right]^{2}}
$$

It should be noted that an $R$ and $E^{2}$ value of 1.0 implies a perfect fit.

Disturbed and undisturbed soil sample data from boreholes were collected from Geospec Sdn. Bhd., Kuching, Sarawak, Malaysia. A total of 144 sample data were used to calculate the hydraulic conductivity of the soil. The most important property of soil for indirectly determining the hydraulic conductivity, $k$, is the $\mathrm{D}_{10}$ value from the particle size distribution graph. Hence in this study, the hydraulic conductivity values have been deduced from the empirical formula given by Shepherd [9]. 


\section{RESULTS AND DISCUSSION}

There are a few important parameters, which contributes to the value of $k$ of the samples, which are moisture content (w), bulk density $\left(\mathrm{Mg} / \mathrm{m}^{3}\right)$, dry density $\left(\mathrm{Mg} / \mathrm{m}^{3}\right)$, void ratio (e), liquid limit (\%), plastic limit (\%), gravel (\%), sand (\%), silt (\%) and clay (\%) and hydraulic conductivity (cm/s).

These parameters have been used in training and testing of the ANN models. Firstly, 100 data values have been used to train the network and the remaining 44 data have been used for testing purposes. The following parameters were analysed and the results are as follows:

Table 1 shows different learning algorithms and their efficiencies. It can be observed from Table 1 that the coefficient of correlation $\mathrm{R}$ of testing for $r p$ is the highest, with a value of 0.8493 . Observing from the variation of $\mathrm{R}$ and $\mathrm{E}^{2}$ values of training, $\mathrm{R}$ and $\mathrm{E}^{2}$ are correlated to each other. A higher $\mathrm{R}$ value will contribute to a higher $\mathrm{E}^{2}$ value. Observing the value of $\mathrm{E}^{2}, r p$ also has the highest value with 0.7209 . Therefore, it can be concluded that the $r p$ algorithm yields the best model.

Table 1. Correlation values of different algorithms with 5000 epochs, 10 neurons in the hidden layer and learning rate 0.03

\begin{tabular}{|c|c|c|}
\hline \multirow{2}{*}{$\begin{array}{c}\text { Training } \\
\text { Algorithm }\end{array}$} & $\begin{array}{c}\text { Coefficient of Correlation, } \\
\text { R (testing) }\end{array}$ & $\begin{array}{c}\text { Coefficient of Efficiency, } \\
\mathrm{E}^{2} \text { (testing) }\end{array}$ \\
\cline { 2 - 3 } & 0.8493 & 0.7209 \\
\hline$r p$ & 0.7140 & 0.4836 \\
\hline Im & 0.6988 & 0.2679 \\
\hline$c g p$ & 0.6952 & 0.2081 \\
\hline$s c g$ & 0.6988 & 0.4682 \\
\hline$c g g$ & 0.6988 & 0.4630 \\
\hline$c g f$ & 0.6988 & 0.3624 \\
\hline$o s s$ & 0.2618 & 0.0198 \\
\hline
\end{tabular}

The overall performances of the 8 training algorithms are with respect to the training and testing coefficients. $r p$ is the training algorithm that yields the best result. The oss algorithm performs poorly and produced the least accurate results in training and testing.

The aim of this study is to find out the optimum number neurons that best suit the network. Figures 1(a) and 1(b) show the performance of $R$ testing and $E^{2}$ testing for networks with epoch 5000 and learning rate 0.03 . As observed from Figure 1(a) and 1(b), low number of neurons may lead to lesser precision of simulated results because like human being, neural network learns by example. Therefore, the larger the number of neurons is "equal” to more people giving feedbacks to the network. This phenomenon creates a network with more learned examples and increases the precision of the simulated results. As of this, number of neurons of $8,10,20$ and 30 will be more suitable because they perform consistently above $50 \%$.

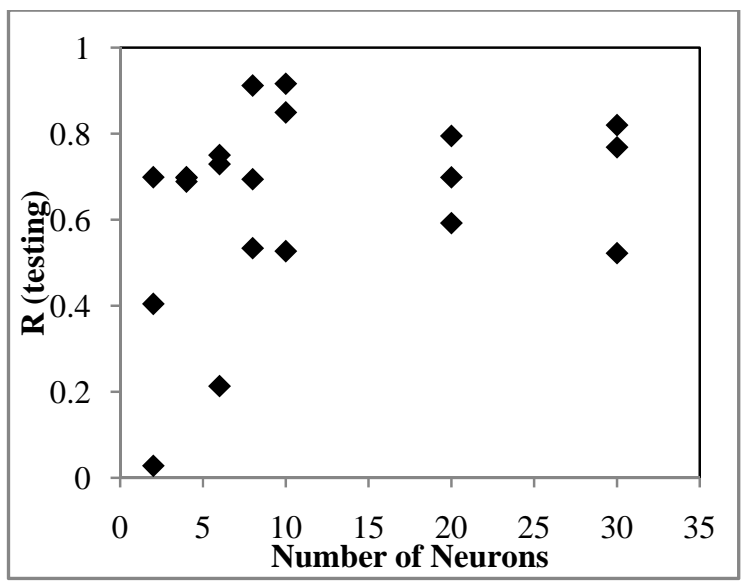

(a)

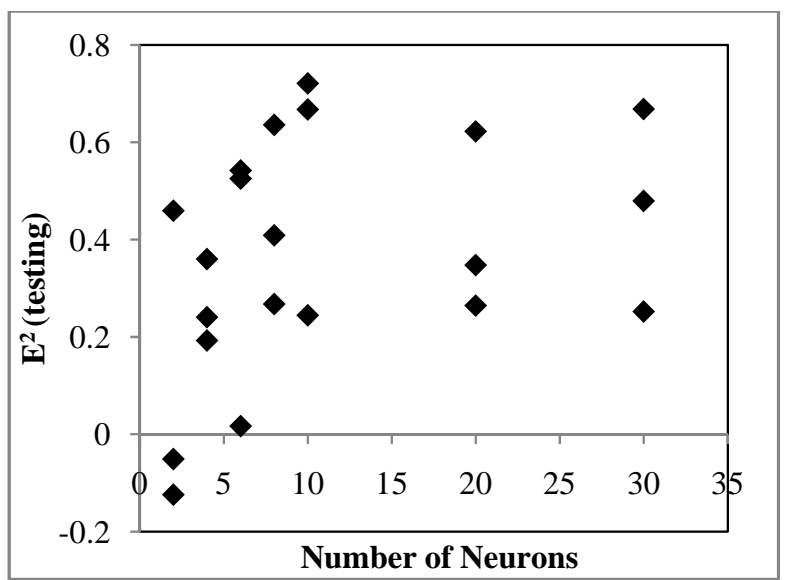

(b)

Figure 1. Performance of neural networks in (a) R for testing and (b) $E^{2}$ for testing using trainrp, with epoch 5000 and learning rate 0.03 
The ratio of $R$ testing ranges from 0.03 to 0.91 whereas, the ratio of $E^{2}$ testing ranges from -0.12 to 0.72 . Comparing both $R$ testing values and $E^{2}$ testing values, we can deduct that the efficiency of $E^{2}$ is lower. The number of neurons which perform at higher efficiency of $E^{2}$ testing will be the suitable for this network. As observed from Figure 1(a) and 1(b), number of neurons of 10 gives the highest percentage in $E^{2}$ testing. Therefore, 10 neurons will be suitable for this network.

Learning rates are utilized in the network to ensure a better training algorithm. Figure 2 compares the performance of different learning rates with number of neurons. Generally, different learning rates do not contribute to any significant differences in training and testing of the network. The larger the learning rate, the bigger the step. However, if the learning rate is set too high, the algorithm may oscillate and become unstable. If the learning rate is too small, the algorithm will take too long to converge. In this study, most learning rates are able to converge in simulating the networks. Learning rate of $0.01,0.03,0.05,0.07$ and 0.09 shows a wide range of $\mathrm{R}$ values from 0.21 to 0.92 . Out of these values, learning rate of 0.03 is most suitable as it produces the highest $\mathrm{R}$ value of 0.92 . Figure 3 shows the results of simulated and calculated hydraulic conductivity, $k$, values trained with trainrp.

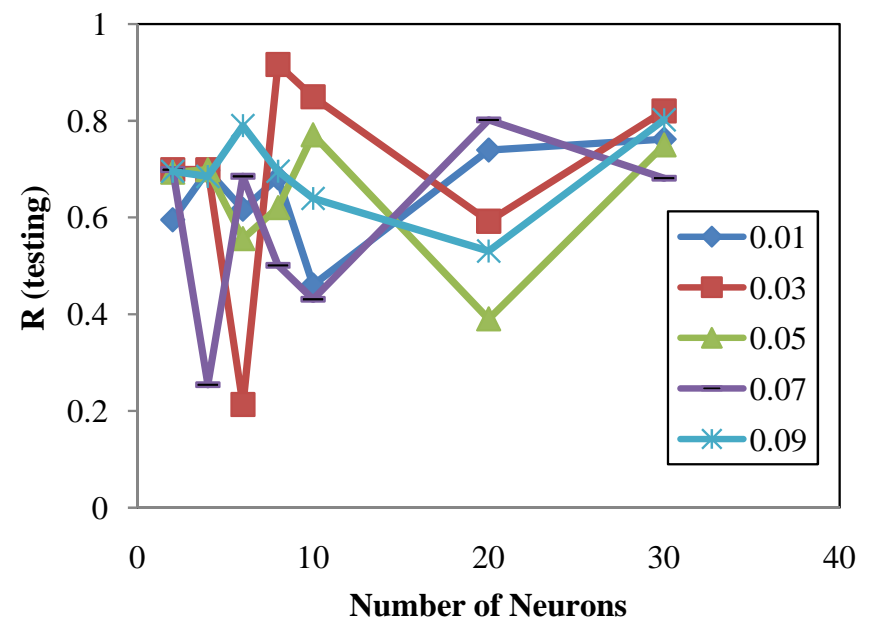

Figure 2. Testing of data according to learning rate.

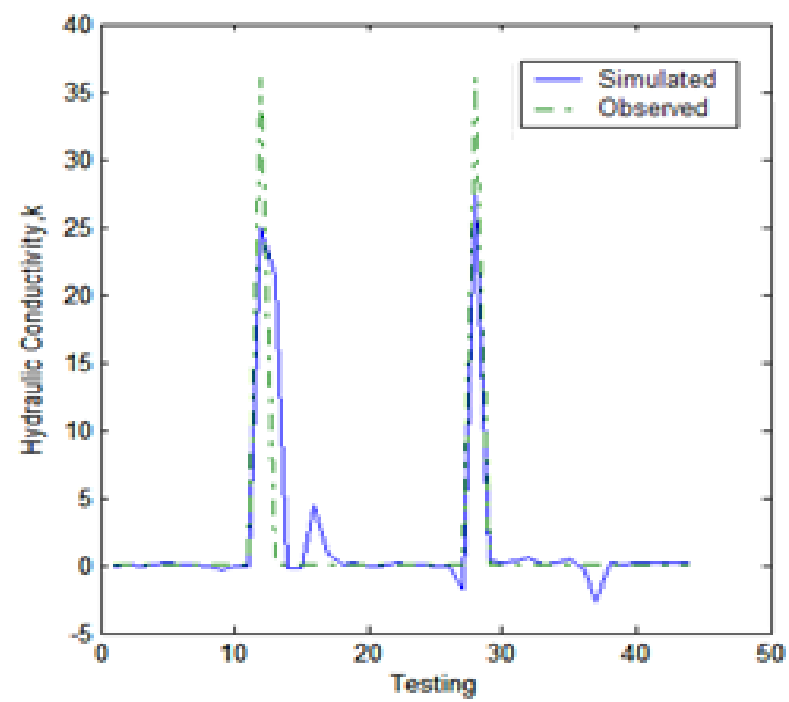

Figure 3. Comparison between simulated and calculated hydraulic conductivity, $k$ trained with trainrp.

\section{CONCLUSiOnS}

In this study an attempt has been made to predict the hydraulic conductivity $(k)$ of tropical soils using the neural network simulation based on the geotechnical properties of various soil types from different borehole testing data. Based on the neural network simulated by MATLAB 6.5.1, the following conclusions can be made: 
i. Network trained with Resilient Backpropagation algorithm (trainrp) consistently simulates the most precise result. Networks trained with One-step Secant (trainoss) algorithm simulate the results with least accurate precision.

ii. A simulation with a bigger number of neurons in the hidden layer shows a better result than simulation with a lower number of neurons.

iii. Different learning rates do not contribute to any significant differences in training and testing of the network. Most values of the learning rates are able to converge in simulating the networks.

\section{ACKNOWLEDGMENT}

The authors are thankful to Mr. Kelvin Huong Tuong Yu, General Manager of Geospec Sdn. Bhd., and Miss Wong for allocating time and providing invaluable borehole data. The authors also thank Bustami, R.A. and Hong, C.C.C. Faculty of Engineering, UNIMAS for their help.

\section{REFERENCES}

[1] Das, B.M. "Principles of Foundation Engineering", $5^{\text {th }}$ Edition, Brooks/Cole. 2004, United States.

[2] Cronican, A.E. and Gribb, M.M. "Hydraulic Conductivity Predicting for Sandy Soils”, Ground Water, Vol. 42, No. 3, 2004 , pp. $459-464$.

[3] Nemati, M.R., Caron, J. and Gallichand, J. "Predicting hydraulic conductivity changes from aggregate mean weight diameter", Water Resources Research, Vol. 38, No. 9, 2002, 1170.

[4] Poulsen, T.G., Moldrup, P., Yamaguchi, T. and Jacobsen, O. H. "Predicting saturated and unsaturated hydraulic conductivity in undisturbed soils from soil water characteristics”, Soil science, Vol.164, No. 12, 1999, pp. 877-887.

[5] Darcy, H. Les Fontaines Publiques de la Ville de Dijon, 1856, Paris.

[6] Richards, L.A. "Capillary conduction of liquids through porous media”, Physics, Vol. 1, 1931, pp. 318-333.

[7] Samarashinghe, A.M., Huang, Y.H., and Drnevich, V.P. "Permeability and Consolidation of Normally Consolidated Soils," Journal of the Geotechnical Engineering Division, ASCE, Vol. 108, No. GT6, 1982, pp. 835-850.

[8] Tavenas, F., Jean, P., Leblond, P., and Leroueil, S. "The Permeability of Natural Soft Clays, Part II: Permeability Characteristics," Canadian Geotechnical Journal, Vol. 20, No. 4, 1983, pp. 645-660.

[9] Shepherd, R.G. "Correlations of permeability and grain-size", Ground Water, Vol. 27, No. 5, 1989, pp. 633-638.

[10] Filz, G.M., Henry, L.B., Heslin, G.M., and Davidson, R.R. "Determining Hydraulic Conductivity of Soil-Bentonite Using the API Filter Press", Geotechnical Testing Journal, Vol. 24, Issue 1, 2001.

[11] Gribb, M.M. and Gribb, G.W. "Use of Neural Networks For Hydraulic Conductivity Determination in Unsaturated Soil”, Proc. 2nd International Conference on Ground Water Ecology, Atlanta (eds. Stanford, J.A., Valett, H.M.), Bethesda MD: Amer. Water Resources Assoc., 1994, pp. $155-163$.

[12] Najjar, Y.M. and Basheer, I.A. "Utilizing Computational Neural Networks for Evaluating the Permeability of Compacted Clay Liners”, Geotechnical \& Geological Engineering, Vol. 14, No. 3, 1996, pp. 193-212.

[13] Boadu F.K. "Hydraulic Conductivity of Soils from Grain-Size Distribution: New Models”, J. Geotech. and Geoenvir. Engrg., Vol. 126, Issue 8, 2000, pp. 739-746

[14] Lee, C. and Sterling, R. “ Identifying Probable Failure Modes for Underground Openings using a Neural Network”, International Journal of Rock Mechanics and Mining Sciences \& Geomechanics Abstracts, Vol. 29, No. 1, 1992, pp. 49-67.

[15] Penumadu, D., Jin-Nan, L., Chameau, J-L. and Arumugam, S. "Rate Dependant Behavior of Clays Using Neural Networks, Proc. 13th Conference of Int. Soc. Soil Mechanics and Foundation Engineering, New Delhi: New Delhi, Oxford \& IBH Publ. Co., Vol. 4, 1994, pp. 1445-1448.

[16] Lee, I. and Lee, J. "Prediction of Pile Bearing Capacity Using Artificial Neural Networks.” Computers and Geotechnics, Vol. 18, No.3, 1996, pp. 189 $-200$.

[17] Sivakugan, N., Eckersley, J.D., and Li, H. "Settlement predictions using neural networks.” Australian Civil Engineering Transactions, CE40, 1998, pp. 49-52.

[18] Kolay, P.K., Bustami, R.A. and Ling, N.W. "Settlement Prediction of Tropical Peat Soil by Artificial Neural Network (ANN)", $12^{\text {th }}$ International Association for Computer Methods and Advances in Geomechanics (IACMAG), Goa, 1-6 Oct 2008, pp. 1843-1849.

[19] Goh, A.T.C . "Seismic Liquefaction Potential Assessed by Neural Networks", Journal of Geotechnical Engineering - ASCE, Vol. 120, No. 9, 1994, pp. $1467-1480$. 